\section{Remote by default general practice: must we, should we, dare we?}

Greenhalgh and Rosen ${ }^{1}$ discuss the opportunities of remote consultation in general practice. They suggest caution before adopting a 'remote by default' strategy ${ }^{2}$ and highlight the lack of goodquality research to support a full switch to remote consultation. ${ }^{3,4}$

In addition to the concerns raised by their editorial, it is important to consider the extent to which vocational training needs to change in order to prepare the future general practice workforce for effective remote consultation. Key recommendations from the Topol review ${ }^{5}$ related to the need for a digital-ready workforce, but current GP training is still based on the premise that most consultations occur face-to-face, with little emphasis on developing phone or video consultation skills.

With support from Health Education England (HEE), we recently surveyed GP trainees in the West Midlands who had been working in general practice during the first wave of COVID-19 to understand how they had been affected by the shift to remote consultation. Fifty-two lout of an estimated 300) trainees responded. Of these, $76 \%$ reported remote consultation had become a key component of their work, but only $9 \%$ felt confident when undertaking such consultations. They reported a lack of formal training in remote consultation and $78 \%$ felt the changed working patterns had affected their physical health and $94 \%$ their emotional/mental wellbeing - with 'stress', 'anxiety', and 'uncertainty about the future' reflected in a number of free-text comments.

While remote consultation is here to stay in one form or another, if we are to train (and retain) capable and competent future GPs, there is an urgent need to review training curricula and programmes to ensure that the right skills development, support, resource, and assessments are available to meet the needs of current and future GP trainees. Our research group is undertaking further research to explore and understand in more detail the training needs of GP trainees relating to remote consultation and how these could be met as part of vocational training programmes.

\section{Bilal Salman,}

Academic Clinical Fellow/ST3, Unit of Academic Primary Care, University of Warwick, Coventry.

Email: B.Salman.11warwick.ac.uk

Sarah Hillman,

NIHR Clinical Lecturer Primary Care, Unit of Academic Primary Care, University of Warwick, Coventry.

Helen Atherton,

Associate Professor, Unit of Academic Primary Care, University of Warwick, Coventry.

Jeremy Dale,

Professor, Unit of Academic Primary Care, University of Warwick, Coventry.

\section{REFERENCES}

1. Greenhalgh T, Rosen R. Remote by default general practice: must we, should we, dare we? Br J Gen Pract; DOI: https://doi.org/10.3399/ bjgp21X715313.

2. Hancock M. The future of healthcare. [Speech, 30 July]. London: Department of Health and Social Care, 2020. https://www.gov.uk/government/ speeches/the-future-of-healthcare laccessed 11 May 2020)

3. Newbould J, Ball S, Abel G, et al. A 'telephone first' approach to demand management in English general practice: a multimethod evaluation. Health Services Delivery Res 2019; DOI: 10.3310/ hsdr07170.

4. Campbell JL, Fletcher E, Britten N, et al. Telephone triage for management of same-day consultation requests in general practice (the ESTEEM trial): a cluster-randomised controlled trial and cost-consequence analysis. Lancet 2014; 384(9957): 1859-1868.

5. Topol E. The Topol review. Preparing the healthcare workforce to deliver the digital future: an independent report on behalf of the Secretary of State for Health and Social Care. 2019. https:// topol.hee.nhs.uk/wp-content/uploads/HEE-TopolReview-2019.pdf (accessed 11 May 2021).

DOI: https://doi.org/10.3399/bjgp21X715925

\section{Readability of general practice websites and the $B J G P$}

Rughani and colleagues' excellent paper ${ }^{1}$ in your May edition examined the readability of Scottish general practice websites lanswer: not very). This naturally begs the question of what would happen if the same tests were applied to your own journal. I have used the Gunning FOG index for this (http:// gunning-fog-index.com/): it was not used in the original article but has the inestimable advantage of being freely available online.

The first paragraph of the first editorial from May 2021 scores 18 on the index. ${ }^{2}$ The first two paragraphs of the first research article score 20.3. The first paragraph of the first 'Life and Times' article scores 18.3. The reading ability of the average university graduate is above 17. On this sample about three-quarters of UK adults would not be able to fully understand a BJGParticle.,.4 Does this matter? The journal is aimed at people who have a degree - GPs. Yet what is the point of making medical journals 'open access' if most of our patients don't know what they are reading? Is jargon justified by the complexity of the concepts that these neologisms refer to? Or could we be accused of an unnecessary complication of words and grammar, and pomposity of language, simply to confuse the laity and promote the status of the profession? [Author's note: FOG index of this letter is 11.6.]

Ed Warren,

Retired GP, Barnsley.

Email: ed.warrenahotmail.co.uk

\section{REFERENCES}

1. Rughani G, Hanlon P, Corcoran N, Mair FS. The readability of general practice websites : a crosssectional analysis of all general practice websites in Scotland. Br J Gen Pract 2021; DOI: https://doi. org/10.3399/BJGP.2020.0820.

2. Gunning R. The technique of clear writing. New York: McGraw-Hill, 1952: 36-37.

3. Ball C. Most people in the UK do not go to university - and maybe never will. Guardian 2013; 4 Jun: www.theguardian.com/higher-education-network blog/2013/jun/04/higher-education-participationdata-analysis [accessed 12 May 2021].

4. Kelly L. Readability and the Gunning Fog Index. 2017. https://readable.com/blog/the-gunning-fogindex/ [accessed 13 May 2021].

DOI: https://doi.org/10.3399/bjgp21X715937 